\title{
EL MERCAT DE L'HABITATGE
}

\author{
Anna Alabart Vilà ${ }^{1}$ \\ Universitat de Barcelona
}

Remisión Artículo: 25-9-2007

Palabras Clave: Evolució de preus dels habitatges, demanda d'habitatge,necessitats d'habitatge.

Resumen: L'article exposa, en primer lloc, les particulars característiques de la demanda d'habitatge, bé de primera necessitat i, alhora, possible receptacle de valor canvi. Analitza després els factors que expliquen l'evolució dels preus dels habitatges, concretant-ho al cas de Barcelona i Catalunya. En segon lloc, passa a considerar les estratègies que persones $i$ famílies han endegat per cobrir les necessitats d'habitatge, referint-se a les solucions que ofereixen el mercat i l'Administració. Finalment mostra algunes de les conseqüències que ha tingut l'encariment de l'habitatge.

\section{L'habitatge: demanda i oferta}

L'habitatge és un bé de naturalesa molt complexa. La complexitat es deriva de ser, alhora, un bé de primera necessitat, fons d'estalvi i bé d'inversió. Tres funcions que al llarg del temps apareixen combinades en intensitats i formes diverses. Darrera, necessitats, desitjos i interessos, que es conjunten i s'enfronten sustentant les corresponents estratègies individuals o collectives.

Les dificultats d'anàlisi augmenten quan es comprova que cada una de les funcions apuntades pot desdoblar-se en una pluralitat de subfuncions. Així, des del punt de vista de l'usuari, l'habitatge no solament és un lloc per aixoplugar-se i l'indret on es desenvolupa la seva vida quotidiana, és també la llar, amb clares connotacions de representació personal i familiar, que com a tal es desitja el millor possible, sent sovint la materialització primera de l'efecte demostració. A més, la demanda d'habitatge pot incorporar primera residència i residències secundàries.

Quan del valor ús de l'habitatge es passa al valor canvi, és a dir, s'introdueixen les seves possibles funcions d'atresorament i d'inversió, la diversitat de combinacions i la complicació d'anàlisi augmenta encara més. Per sistematitzar, i simplificant-ho molt, es poden considerar dues possibilitats extremes: la que és prop de la funció d'estalvi (manteniment de valor, efecte seguretat, garantia de qualitat de vida...); la funció inversió especulativa (que en el seu punt màxim es concretaria en pràctiques abusives).

El que s'acaba d'apuntat constitueix la base, els pilars primers, sobre la qual recolzar les explicacions de les dinàmiques d'encariment de l'habitatge: una demanda ciutadana disposada a pagar tant com li sigui possible per obtenir un lloc on viure; uns agents urbans (constructors, promotors i propietaris del sòl) bolcats a maximitzar els seus beneficis, que aprofiten estructura i conjuntura per aconseguir millorar o mantenir la seva posició en el mercat. Pel mig, l'administració actuant "subsidiàriament" per cobrir les necessitats de la demanda que compta amb pocs o nuls recursos; garantint -en moments de desacceleració del creixement econòmic - que es mantingui l'activitat constructora $i$, sobretot, el muntant de llocs de treball

\footnotetext{
${ }^{1}$ Persona de contacto Grup de recerca Territori, Població i Ciutadania, correu: grptcb@upc.edu
} 
que genera; evitant que l'explosió de bombolles immobiliàries puguin generar turbulències financeres que frenin l'economia i amenacin la pau social.

\section{L'evolució dels preus dels habitatges}

A partir de 1986 les grans ciutats espanyoles, i Barcelona en particular, es van veure sorpreses per un increment inusitat del preus dels habitatges. Inusitat per la seva intensitat; inusitat perquè esdevingué sobtadament. Podria pensar-se que la crisi econòmica, iniciada a les darreries dels anys setanta, havia tingut un efecte de contenció i, que coincidint amb el final del cicle baix, els preus es dispararen. Certament aquest és un factor a tenir en compte, però sobretot la causa cal buscar-la en un element psico-econòmic: l'habitatge assoleix caràcter de bé canvi amb elevades expectatives de rendiments creixents.

Quins són els elements desencadenants del procés? N'hi ha un feix. Entre els més importants: el crak bursàtil; la necessitat de col-locar diner negre, davant el progressiu control fiscal; l'entrada d'Espanya en el Mercat Comú; el nomenament de Barcelona com a candidata a seu Olímpica i, el Decret Boyer que, alhora que permet la utilització del pisos com a seus de negoci, facilita la desgravació de la inversió en immobles i inicia la liberalització dels lloguers. Barcelona, amb notables valors naturals i simbòlics, es posa de moda i els preus dels seus habitatges són, comparativament amb la resta d'Europa, força baixos.

Tot plegat excel.lents condicions per a una inversió empresarial segura i amb possibilitat d'elevats rendiments. Dues van ser les dinàmiques més freqüents seguides pel sector negocis: la primera situar la seu de l'empresa i els seus despatxos directius en els llocs més cèntrics i simbòlics de les grans ciutats. El cost de la instal-lació va esdevenir una inversió rendible. La generalització de la informàtica els permeté establir-se relativament lluny de les plantes de fabricació, magatzematge i distribució. En segon lloc, els inversors podien comprar per tornar a vendre, segurs com estaven de la pujada de preus a curt termini. El sector negocis va passar a engrossir la demanda de pisos a les ciutats, competint amb les famílies i els ciutadans.

A les qüestions anteriors cal afegir-hi l'entrada de generacions molt plenes --corresponen ja al baby boom-- en l'edat d'emancipar-se i formar una nova llar. Malgrat el seu poder adquisitiu no fos gaire elevat, el fet de constituir una nombrosa demanda potencial, reforçava, encara més, expectatives i preus. D'altra banda, la sortida de la crisi va millorar la seva situació en el mercat. Molts d'ells es van convertir en demanda efectiva si bé sovint van haver de renunciar a viure a les grans ciutats $\mathrm{i}$, fins $\mathrm{i}$ tot en el centre dels municipis.

Aquest escenari es va mantenir entre 1986 i 1994. A partir de 1994 -i com a conseqüència d'una certa recessió econòmica - els preus dels habitatges s'estanquen i fins i tot davallen lleugerament. Però, en arribar 1997 de nou la corba de preus s'enfila, esperonada, aquest cop, per la imminent entrada en funcionament del patró l'euro ${ }^{2}$, pel continuat abaratiment del diner i, novament, per les expectatives d'uns beneficis derivats del fort increment dels preus de I'habitatge. Encara hi ha un altre element que s'hi afegeix i reforça els anteriors: és la llei de 1998, que en liberalitzar el sòl multiplica les oportunitats de benefici en negocis immobiliaris.

Fins aquí res no s'ha dit en relació amb l'època de construcció de l'habitatge. No s'ha diferenciat entre aquells que són de nova planta i els de segona mà. I és que a Barcelona, com a la resta d'Espanya, les diferències de preu entre els uns i els altres són mínimes, com permet comprovar el Gràfic 1 . Aquesta circumstància té molta importància alhora d'explicar l'elevat preu dels lloguers. De tota manera, a partir del 2004, 2005, quan els tipus d'interès comencen a augmentar -tot i que molt lleugerament- l'increment dels preus de segona mà es modera i el

\footnotetext{
${ }^{2}$ La incertesa va decidir molts a executar les operacions de compra.
} 
$\mathrm{m}^{2}$ de sostre se situa clarament per sota dels corresponents a la nova construcció. Pot esperarse que aquesta tendència es mantingui en el futur, donant lloc a dos mercats prou diferenciats.

El gràfic que segueix recull l'evolució els preus del $\mathrm{m}^{2}$ de l'habitatge a Barcelona des de 1975 a 2006 i permet observar l'existència dels tres moments abans apuntats. Corresponen i van lligats al creixement econòmic: quan aquest s'activa, els preus dels habitatges incrementen; quan es frena, també ho fan el increments dels preus.

\section{Gràfic 1: Evolució dels preus de venda de l'habitatge a BCN}

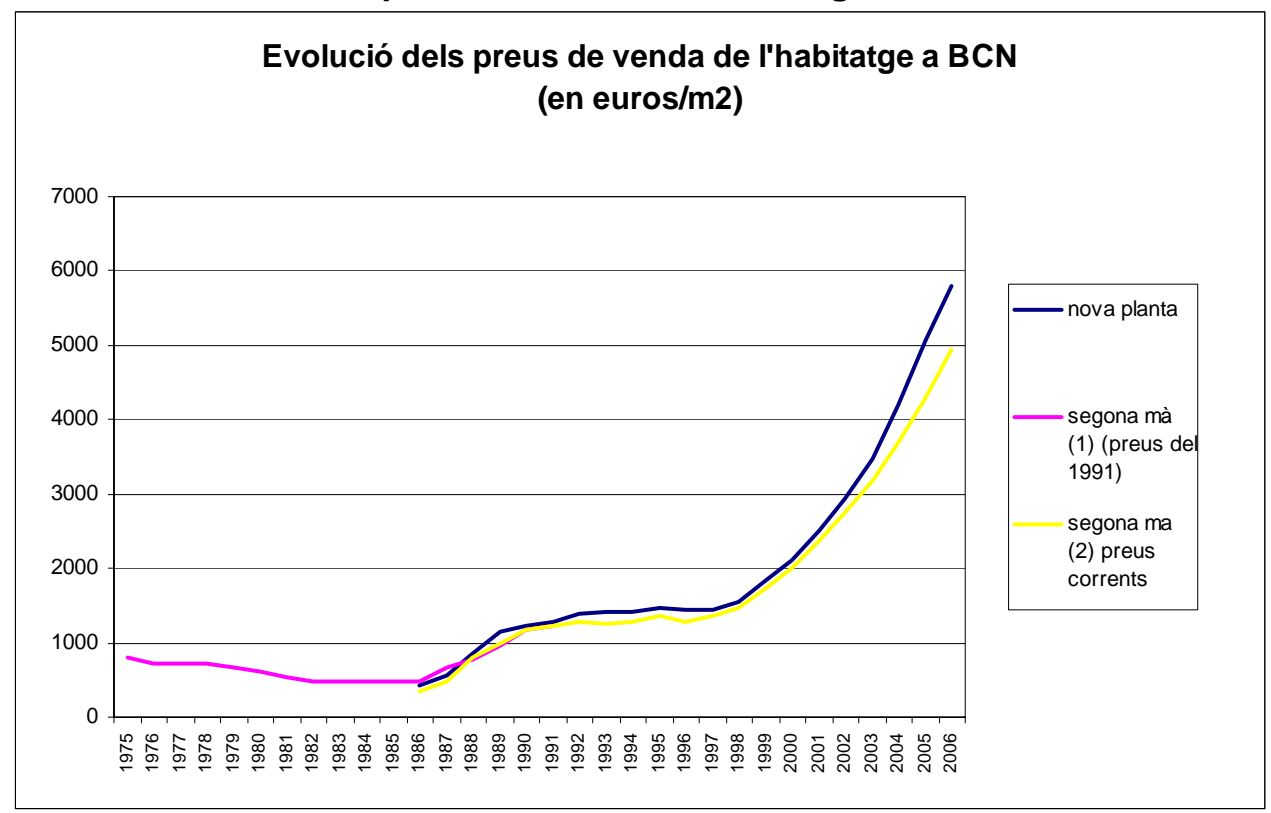

Font: Elaboració pròpia a partir de les dades de e Barcelona Economia. Nova Planta, fins l'any 2000: Núm. 45, pág. 54; 2001-2004: Núm. 57, pàg. 56 (en Euros); 2006: Num. 61, pàg. 56 en Euros), Núm 63, pàg 58 (en Euros) Preus de segona mà (1): Núm. 15, pág. 90 Preus segona mà (2): fins l'any 2000: Núm. 45, pág. 54; 2001-2004: Núm. 57, pàg. 56 (en Euros) i Núm 60, pàg 58

1) El període 1986 a 1994, correspon al primer moment comentat abans: sortida de la crisi econòmica, creixement econòmic i preus a l'alça. El preu del $\mathrm{m}^{2}$ de sostre construït s'incrementa, tant si és de nova construcció com si és de segona mà.

2) De 1994 a 1997, aturada econòmica i paral.lela contenció dels preus de l'habitatge. Fins i tot s'observa una lleugeríssima reducció.

3) A partir de 1997, s'inicia un llarg període d'onze anys caracteritzat per un creixement econòmic continuat. Continuat ha estat també l'increment de preus de l'habitatge.

Durant aquests anys, i com ja s'ha apuntat, els tipus d'interès es redueixen -tant per a les hipoteques com per a la majoria de les inversions- $i$, el diner barat anima a comprar cases i pisos. Els constructors ho veuen clar: no sols podran vendre més sinó que podran cobrar més (els interessos ja no pressionen sobre els preus de les hipoteques). El resultat serà que com més baixen els interessos hipotecaris, més augmenten els preus del $\mathrm{m}^{2}$ construït (gràfic 2) 
Molts altres factors se sumen a la constitució d'una demanda molt forta que pressiona els preus a l'alça:

- L'ampliació de la demanda estrangera de segones residències (bàsicament europea), incidirà en el mercat de l'habitatge pressionant els preus de les urbanitzacions a l'alça, emparada en la facilitat i seguretat transaccional que l'euro implica.

- Efectes similars, tot i que menys destacables, té la immigració estrangera que afecta, sobretot, el mercat d'habitatges dels nuclis urbans.

- Els inversors tornen, com van fer en la segona meitat de la dècada dels anys vuitanta, a utilitzar els habitatges com un producte especulatiu. La tendència clarament alcista dels seus preus, els proporcionen beneficis clarament superiors als d'altres alternatives.

- A més, l'entrada en escena de la Llei dels sòl i valoracions de 1998, en introduir el valor expectant com a base de càlcul per a les transaccions de terrenys, i la consideració de que tot sòl que no fos protegit pogués ser urbanitzat, acaba de completar el marc per a les actuacions especulatives: la bombolla immobiliària i l'ocupació i construcció d'àmplies zones de sòl amb la tècnica del pelotazo, resulten ser les conseqüències escandaloses més visibles del procés.

- Quan, en el darrer període, els tipus d'interès tornen a remuntar, l'increment del preu de l'habitatge ho acusa reduint el seu creixement $i$, en especial, el corresponent a l'habitatge de segona mà. Però d'això se'n tractarà al final ja que la relantització va acompanyada d'incertesa i de temors a una nova crisi econòmica i a una explosió sobtada de la "bombolla immobiliària".

\section{Gràfic 2: Evolució del preus de l'habitatge}

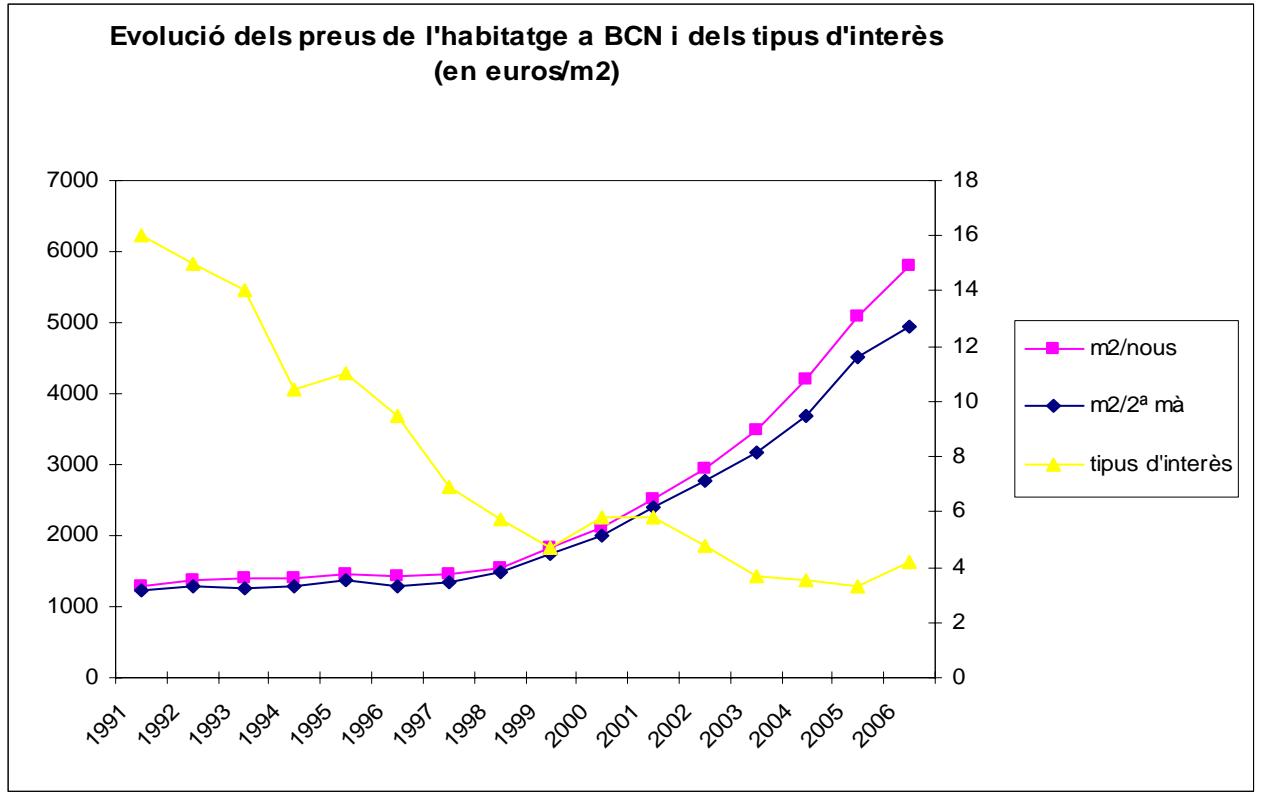

Fonts: Elaboració pròpia a partir de les dades de e Barcelona Economia, Nova Planta, fins l'any 2000: Núm. 45, pág. 54; 2001-2004: Núm. 57, pàg. 56 (en Euros); 2006: Num. 61, pàg. 56 (en Euros) Preus segona mà, fins l'any 2000: Núm. 45, pág. 54; 2001-2004: Núm. 57, àg. 56 (en Euros, i Núm 60 , pàg 58 Tipus d'interès de les hipoteques: Núm 60, pàg. 67

A la dreta: preu mig en Euros de l'habitatge a Barcelona; A l'esquerra: tipus d'interès. 


\section{El dret a l'habitatge: estratègies de les famílies, el mercat i l'Administració}

A Espanya el dret a comptar amb un habitatge digne, tot i estar reconegut per la Constitució ${ }^{3}$, es deixa en mans del mercat. L'Administració sols actua subsidiàriament per resoldre casos desesperats o per ajudar la demanda poc solvent a accedir a un habitatge. El lloguer públic és quasi inexistent i les polítiques públiques s'orienten cap a la propietat protegida, en totes les seves variants ${ }^{4}$. La majoria de ciutadans, per tant, han de cercar en el mercat la solució a les seves necessitats d'hàbitat.

Si el mercat és la forma més habitual de cobrir la necessitat d'allotjament, caldrà que el ciutadà disposi de poder adquisitiu, que sigui demanda solvent. Contràriament el mercat no tindrà en compte les seves necessitats ${ }^{5}$. Quines són llavors les formes d'obtenir un habitatge quan no es disposa d'un capital elevat? Les estratègies depenen de les característiques personals i familiars, però essencialment tres són les estratègies ${ }^{6}$ :

1) Retardar l'emancipació.

2) Emancipar-se, generalment amb la col-laboració de la família.

3) Transcendir l'interès propi i cercar formes de denúncia del problema tot proposant possibles solucions alternatives. De fet, més que formes de resoldre el seu problema individual, són moviments socials. Aquest seria el cas dels okupes en les diverses modalitats. Seria també el desl qui es mobilitzen denunciant "que nos passa? Que no tenemos casa"

Les estratègies apuntades poden combinar-se $\mathrm{i}$ desenvolupar-se successivament 0 simultàniament. Fins $\mathrm{i}$ tot, poden ser -i de fet són- reversibles: es veuen obligats a anar $\mathrm{i}$ retornar i repetir-ho a vegades més d'un cop ${ }^{7}$.

El retard en l'emancipació va ser la primera reacció dels joves davant de la crisi econòmica de finals dels anys setanta. Així, a Catalunya, es comprova com, mentre l'any 1980 bastant més la meitat de la població de 20 a 35 anys estava emancipada (el 58\%), l'any 1999 sols ho estava el 35\%. Després, mostrant una clara sensibilitat amb la conjuntura econòmica, s'inicia una certa recuperació que apunta cap al retorn a la dinàmica iniciada abans dels anys més crítics ${ }^{8}$.

En tots els casos -així ho mostren les diverses enquestes on s'indaga sobre la qüestió- són les famílies (en especial les mares) les qui, junt amb els joves, suporten els costos de l'ampliació

\footnotetext{
${ }^{3}$ Article 47 de la Constitució espanyola: "Todos los españoles tienen derecho a disfrutar de una vivienda digna y adecuada. Los poderes públicos promoverán las condiciones necesarias y stablecerán las normas pertinentes para hacer efectivo este derecho, regulando la utilización del suelo de acuerdo con el interés general para impedir la especulación"

${ }^{4}$ En aquests moments tres són els tipus d'habitatge protegits: els de protecció oficial d'accés a la propietat; els de preu concertat $\mathrm{i}$ els dotacionals. Aquests darrers són els únics que es destinen a lloguer i van dirigits a població a amb problemes específics (joves, vells...)

${ }^{5}$ Que no tingui en compte les seves necessitats no significa que no tingui un cert paper en la determinació dels preus: en constituir un possible demandant (encara que sols sigui potencial) juga un paper d'enfortiment de la demanda i per tant pressiona els preus a l'alça, com ja s'ha comentat abans.

${ }^{6}$ A partir d'aquí l'exposició d'aquest punt se centrarà en el col-lectiu de persones joves.

${ }^{7}$ A. López Blasco i M. Du Bois-Reymond han parlat de la generació del "yo-yo". "Transiciones tipo YO-YO y trayectorias fallidas: hacia las políticas integradas de transición para los jóvenes europeos", a Estudios de Juventud, núm. 65. 2004.

${ }^{8}$ L'any 2005 la taxa d'emancipació dels joves catalans (de 20 a 35 anys) tornava a superar el 50\%, segons dades de P. García (dir. i coord.), Problemàtica de l'habitatge dels joves a Catalunya. CPSV. UPC. Barcelona, 2006.
} 
de les possibilitats, sent les de més nivell socioeconòmic les que més es poden permetre el perllongament de la dependència dels fills ${ }^{9}$.

L'emancipació i la formació d'una nova llar es pot fer amb l'ajut de la família o sense. En el primer cas, el conjunt d'estratègies que se segueixen poden ser resumides, fonamentalment, en dues opcions:

a) Quan la família té recursos, comptar amb la seva ajuda per cobrir una part més o menys important del preu de l'habitatge. La resta: una hipoteca, amb freqüència avalada per la pròpia família.

b) Utilitzar la residència secundària (o el "terreny") d'algun familiar (pares, avis) convertintla en principal. Aquesta pràctica ha estat un dels elements que ha incidit en l'expansió de l'urbanisme dispers ${ }^{10}$.

Quan es compta amb pocs recursos personals i familiars, les estratègies es diversifiquen, responent, amb variants, a una de les següents opcions:

c) Comprar un pis a partir d'una hipoteca que cobreixi tot el valor de l'habitatge. Si es perd l'ocupació es perd l'habitatge. Abans tampoc es tenia res ${ }^{11}$. A més, si el mercat manté la tendència alcista, pot ser que el producte de la venda permeti pagar l'entrada d'una altra. Pot ser que encara en sobri una mica. Mentrestant la família pot ser l'aixopluc.

d) Llogar un pis, sol o amb la parella o amb diverses persones. El problema és trobar-lo: són cars ${ }^{12}$ i n'hi ha pocs. A més, els propietaris no sempre volen llogar-los a joves o a persones que visquin en grup.

e) Arreglar-se un pis de propietat barat. A vegades s'utilitzen fórmules properes a la masoveria urbana ${ }^{13}$

Pel que fa a la darrera de les opcions, la que es refereix a la okupació està clar que més que una alternativa per satisfer una necessitat és un crit d'alerta propi d'un moviment social, per la qual cosa depassa l'objectiu d'aquest article. ${ }^{14}$

\footnotetext{
${ }^{9}$ L. Garrido i M. Requena, La emancipación de los jóvenes en España. Instituto de la Juventud, Ministerio de Trabajo y Asuntos Sociales. Madrid, 1999.

${ }^{10}$ A partir de la informació que s'ha obtingut en l'estudi Solidaridad Familiar y Ciudadanía en las Regiones Metropolitanas, finançat pel Ministeri d'Educació i Ciència, podem afirmar que a l'entorn d'un $15 \%$ dels qui viuen en urbanitzacions disperses situades a la Regió Metropolitana de Barcelona estan utilitzant habitatges que, en origen, eren segones residències familiars.

${ }^{11}$ De tota manera el mercat, com després es comentarà, ofereix alguna solució per a aquesta emergència (naturalment cara): mitjançant una assegurança, hi ha modalitats hipotecàries que permeten deixar de parar les quotes durant un any en cas de necessitat.

${ }^{12}$ A més de ser cars, van augmentant en una proporció superior a l'IPC: així entre setembre de 2005 i setembre de 2006, els lloguers espanyols han augmentat un 4.3\%, quan l'IPC ho ha fet en un $2.9 \%$ durant el mateix període. L'explicació cal cercar-la en el que es comentava en el punt anterior : els preus de venda dels pisos de segona mà són similars, i han anat augmentat en paral-lel, als de nova construcció, per tant el que determina el càlcul del lloguer no és el preu de compra sinó el possible preu de venda.

${ }^{13}$ S'arriba a un acord amb el propietari segons el qual els llogaters milloraran I'habitatge i, en compensació, el lloguer serà més barat.

${ }^{14}$ Sobre la qüestió pot consultar-se el text de la intervenció A. Alabart i J. Gavaldà: Els joves i l'habitatge, feta a en el context de la IX Setmana d'Estudis Urbans - Universitat de Lleida, a l'octubre de 2006.
} 
Així les coses, mercat i Administració s'afanyen en resoldre els principals entrebancs. L'un per aconseguir incrementar les possibilitats de benefici; l'altra per a mantenir la pau social i el creixement econòmic. En ambdós casos el discursos es maquillen: es vetlla pel consumidor $i$ pels seus drets, afirmen els del primer; són els drets bàsics dels ciutadans, diuen des de les administracions. L'anàlisi de les estratègies i polítiques recents ho il.lustra.

El mercat fa el que pot per no perdre clients: aconsegueix que, a partir del sector financer, s'ampliïn les possibilitats efectives de les persones 0 , a partir de les possibilitats dels promotors i constructors, diversifica les ofertes d'habitatge per respondre a l'amplia tipologia de demandes.

Exemplificant: en relació amb la primera estratègia hi són les hipoteques, de les quals s'ofereix una notable varietat de formes i condicions. Això sí, totes cares.

- Hipoteca jove: els terminis d'amortització s'amplien fins els 30, 35 i 40 anys. Les dues darreres fórmules sols son utilitzables pels joves (menys de 36 anys (sic!)). No és qüestió de que estiguin pagant més enllà dels 85 anys!. Un termini tan llarg requereix assegurances perquè no estaria bé que les entitats financeres carreguessin amb tot el risc de possibles traspassos dels seus clients.

- Hipoteca amb assegurança d'atur: sensibles a deplorables imprevistos, tals com que els clients es quedin en atur, es preveu que si això es dóna i previ contracte de la corresponent assegurança- es pugui estar un any sense pagar les quotes.

- Hipoteca recarregable: Permet anar ampliant la quantia pendent d'amortitzar, sempre i quant no se superi el límit inicialment contractat.

Hi ha moltes més modalitats: hipoteca compartida, hipoteca ajornada... Es una de les estratègies que s'ofereix als demandants d'habitatge. Si, malgrat les "facilitats", arriba un moment que no poden sufragar les quotes, sempre tenen la solució de vendre. Si aguanten, al final dels seus dies podran tenir un habitatge de propietat.

Una altra de les estratègies que facilita el mercat té a veure amb la tipologia de l'habitatge: diferenciat segons localització -pel preu d' $1 \mathrm{~m}^{2}$ de sostre a la ciutat de Barcelona, es poden obtenir $2 \mathrm{~m}^{2}$ a l'àrea metropolitana (27 municipis de l'entorn) i $3 \mathrm{~m}^{2}$ a la resta de la RMB (164 municipis); grandària i qualitat, s'ofereixen productes adaptats a les possibilitats dels clients. I, així es pot explicar que mentre els diaris afirmen en els seus titulars que el preu dels habitatges $\mathrm{s}$ 'ha mantingut $\mathrm{o}$, fins $\mathrm{i}$ tot ha baixat, quan s'analitza el preu del $\mathrm{m}^{2}$ corresponent a un determinat indret, aquest ha continuat pujant. Es el que ha succeït darrerament a la ciutat de Barcelona: el $\mathrm{m}^{2}$ de sostre ha pujat però els pisos nous han reduït els seus preus a base de disminuir també la seva superfície: cada cop hi ha més estatge d'una o dues habitacions ${ }^{15}$. Es clar que també hi ha immobiliàries que aposten pels "habitatges d'autor"16

L'Administració, almenys en teoria, actua, d'una banda com a subsidiària del mercat i de l'altra dictant i vetllant pel compliment d'unes lleis que incrementin l'equitat, ja que no poden aconseguir-ho en termes absoluts. Lleis del sòl; plans d'urbanisme; Llei de barris; lleis

\footnotetext{
${ }^{15}$ el País, al 29 de novembre de 2006 (pàg. 44 Catalunya): Segons dades de l'Associació de Promotors i Constructors, l'habitatge, a Barcelona costa 7.997 euros $/ \mathrm{m}^{2}$. Els pisos són cada cop més petits, però segueixen pujant: el preu per metre quadrat segueix pujant. La vivenda mitjana a la província de Barcelona costa 5.258 euros, m2; a Barcelona, 7.997 euros $\mathrm{m} 2$.
}

${ }^{16}$ El País. Divendres 8 de desembre de 2006. Propiedades, pàg. 1 i 5 
relacionades amb l'habitatge i amb la rehabilitació d'espais per a viure; ajuts a les persones o a determinats col-lectius (joves, immigrants...), deduccions fiscals, intermediació... són algunes de les seves actuacions. Ho deixem solament apuntat perquè d'entrar-hi hauríem de doblar les pàgines fins aquí escrites $\mathrm{i}$, a més, és l'objecte d'un altre dels articles que es presenten en aquest mateix número.

En canvi sí volem referir-nos a un darrer punt ja enunciat al principi: fer un rastreig d'algunes de les conseqüències que es deriven de l'encariment del preu de l'habitatge i del fet de deixar-lo en mans d'un mercat que ni té lliure competència (multitud d'oferents/multitud de demandants) ni és un mercat transparent, ni és un mercat flexible.

\section{4.-Algunes de les conseqüències de l'encariment de l'habitatge.}

Del conjunt de conseqüències que es deriven de l'encariment dels habitatges, unes estan lligades a (1) qüestions materials, econòmiques; d'altres tenen a veure amb aspectes (2) psicosociològics $\mathrm{i}$, finalment, $\mathrm{n}$ 'hi ha que tenen a veure amb d'altres amb la pròpia (3) ètica ciutadana. Intentem exposar-ho breument.

Si es comença per les qüestions materials no pot oblidar-se que, a causa de l'encariment de l'habitatge, la gent ha d'anar a viure cada cop més lluny de les grans ciutats, i fins i tot, dels centres dels municipis, donant lloc a la dispersió residencial. Això comporta un fort increment dels costos ecològics, energètics, de desplaçament i temps ${ }^{17}$. A més, i com hem tingut ocasió de comprovar a partir d'un treball de camp específic ${ }^{18}$, la llunyania en relació a la família i als amics repercuteix directament en la reducció de les relacions i dificulta la solidaritat familiar i veïnal. Tot plegat sovint acaba afectant la possibilitat d'ampliar la formació (capital humà) i de desenvolupar les relacions (capital social). Exposar aquestes derivacions requeriria força pàgines i per això, com a apunt, s'ha optat per oferir el testimoni d'una entrevistada que viu en una urbanització del Vallès Oriental, i que, en poques paraules, es refereix als punts enunciats:

"Trabajamos de donde nos hemos ido. Aquí hay más gasto y más de todo. (...)

Antes era diferente: el crío podía ir y venir solo. Aunque era más pequeño, el cole lo tenía cerca. Luego teníamos vecinas. Si yo no estaba le daba de comer. A veces yo me quedaba su niña. Era diferente. (...)

Además, "Si el niño se pone enfermo, cómo lo resuelvo? Antes tenía vecinas y se podía quedar con una o con otra. Aquí no. ¿Aquí con quién lo dejas?

Ahora el niño me tiene muy atada. Entonces, no puedo yo... hacer lo que yo quiera. Hay cosas que querría hacer pero no puedo. Porque sino, él aquí no se puede mover.

No puedo contar con nadie (para que me ayude). No tengo a nadie. (...) Mi madre vive en Barcelona. Como para echarte una mano! “

Dona. Llliça d'Amunt. Mitjana baixa ${ }^{19}$

El paràgraf transcrit requereix pocs comentaris: increment del temps de desplaçament a la feina; increment de les despeses; increment del temps que cal dedicar als menors; reducció de les relacions de reciprocitat (veïnals, familiars); impossibilitat de fer el que es desitjari, etc.

\footnotetext{
${ }^{17}$ Per exemple, en el Vallès Oriental els desplaçaments fora de la comarca s'han triplicat entre 1986 i 2001 y, entre 1999 i 2004 el parc d'automòbils ha incrementat un 43\%

${ }^{18}$ Grup de Recerca de Territori, Població i Ciutadania de la UB (2006): Solidaritat familiar i ciutadania en l'urbanisme dispers.

${ }^{19}$ ibídem. Estudi qualitatiu.
} 
En segon Iloc, i com a conseqüència directe de l'encariment de l'habitatge, apareix l'endeutament de les famílies ${ }^{20}$. La UE ha alertat de l'elevat el risc que endeutament implica ${ }^{21}$.

Directament relacionat amb l'endeutament hi ha l'esforç que han de fer les famílies per pagar les hipoteques. Tot $\mathrm{i}$ que, aquest esforç es va reduir notablement com a resultat de la continuada davallada dels interessos i de l'allargament del temps de cadència, ara amb l'increment dels tipus d'interès, les hipoteques s'han encarit de tal manera que s'ha disparat l'alarma ${ }^{22}$.

Efectivament, el gràfic que segueix mostra, per al cas de Barcelona, l'evolució de l'esforç de les famílies en matèria d'habitatge:

Gràfic 3: Cost financer de l'amortització. Amb l'aportació del conjunt de la llar Barcelona

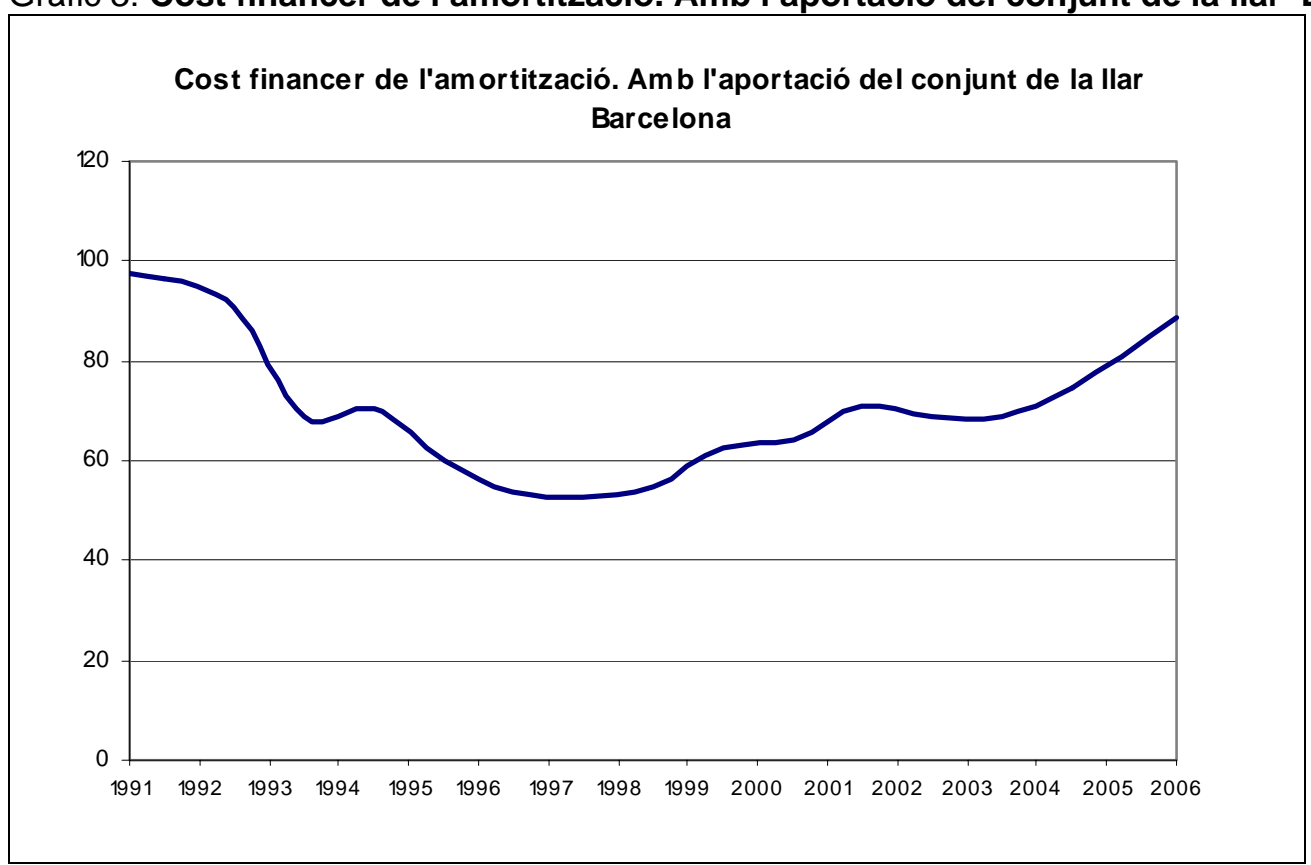

Font: Barcelona Economia, núm. 63

En el Gràfic 2 s'observava la relació inversa entre els tipus d'interès i els preus. Ara, en estudiar l'evolució de l'esforç financer de les famílies es fa palès que no van ser aquestes les beneficiàries de l'abaratiment del diner: a partir de 1998 el seu esforç econòmic augmenta malgrat la continuada reducció dels interessos hipotecaris, que registren mínims històrics en el període 2003-2005. En realitat, els beneficiaris últims dels baixos interessos han estat els promotors i constructors. I això, mitjançant dues dinàmiques paral-leles: d'una banda van poder

\footnotetext{
${ }^{20}$ Segons dades fetes públiques per INE, el setembre de 2006, la hipoteca mitjana espanyola ascendia a 145.313 euros. Aquest import variava molt segons comunitats, sent Madrid i País Basc on són mes elevades (222.000 i 220.000 euros, respectivament) i Extremadura i Galícia on tenen les més baixes .

${ }^{21}$ Des de Brussel-les s' ha denunciat el problema. Un problema que no és sols d'Espanya, tot i que aquest país es troba entre els que estan en major situació de risc, perquè els preus de les seves vivendes són molt alts (i si el punxa la bombolla) la situació material i moral por esdevenir preocupant. (el País, 23 d'octubre, 2006, pàg. 73. Economia) 22

La crisi hipotecària als Estats Units d'Amèrica (EUA) ha mostrat que l'alarma no era espúria: realment ha trontollat l'economia. La UE va reaccionar no incrementant els tipus d'interès i els EUA han baixat avui (20 de setembre de 2007) els seus. L'economia sembla estar recuperant estabilitat.
} 
incrementar la producció immobiliària perquè el diner barat esperonava la demanda; d'altra banda van augmentar el preu del $\mathrm{m}^{2}$ construït perquè el diner barat els permetia fer-ho.

De tota manera, ja a partir de finals de 2005, el risc de que els interessos augmentin comença a amoïnar les famílies, especialment les dels més joves. A l'esforç material ${ }^{23}$ (endeutament de les famílies) s'hi afegeix, doncs, un desgast psíquic (por, intranquil.litat, inseguretat...) a vegades lligat amb altres aspectes de la vida o de l'economia (risc de perdre la feina, quan cada cop hi ha més treball precari ${ }^{24}$ ).

Però si l'encariment de l'habitatge té importants conseqüències materials i psíquiques, també en té de socials. Novament sols apuntar-les: el risc econòmic i intranquil-litat psíquica és, com tantes vegades s'ha dit, la garantia de l'ordre social ${ }^{25} \mathrm{i}$, com tot ordre social que es deriva de la dominació, amb elevada probabilitat d'anul.lació de l'esperit crític o, al menys, de la seva manifestació pública. També de pot derivar en episodis d'anomia (contradicció normativa) tant personals com socials: quan comprem o lloguem un pis volem que sigui el més barat possible; quan el venem en volem treure el màxim; volem que baixin els preus dels habitatges, però alhora, calculem quant hem guanyat en la compra del nostre pis o apartament.

Donant un altre gir de volta al cargol, podem arribar a parlar d'alienació i subversió de valors: s'acaba per tenir actituds canallesques, a les que cada vegada es concedeix menor importància (laxitud de consciència) $\mathrm{i}$ per a les que es cerquen justificacions ad hoc (dissonància cognitiva). A l'article Lo imposible es posible, Isaac Rosa escriu: “...pero por debajo de esa gran corrupción (s'éstà referint als qui es dediquen al negoci immobiliariespeculatiu) se adivina una descomposición mucho más amplia, que nos convierte a todos, tarde o temprano, en pequeños especuladores ${ }^{26}$.

Més encara, la qüestió ha dividit la societat entre els qui tenen o no habitatge (patrimoni). Fins i tot s'ha apuntat com a conflicte generacional. Ara, quan les hipoteques augmenten sota la pressió dels interessos, una nova divisió s'apunta: els qui ja fa temps que estan pagant i els qui tenen el seu pis recent comprat. I la veu desesperada, sobretot dels darrers: "Si lo llego a saber seguiría en alquiler": fa tres anys que han comprat el pis i ara les quotes els han pujat un $50 \%$. Ja no poden afrontar-les. L'única solució és vendre ${ }^{27}$.

Evidentment, el problema depassa la casuística personal i s'ha convertit en social i ara l'Administració està cercant mil maneres d'intervenir-hi. El mercat deixa de ser el principal mecanisme distribuïdor d'un producte que mai no s'hauria hagut de deixar-se exclusivament a els seves mans.

\footnotetext{
23 Les dades del Gràfic 3 s'han calculat a partir de les rendes mitjanes dels barcelonins i referides a la compra d'un habitatge a Barcelona, havent subscrit una hipoteca de 19 anys fins el 1998 i de 20 anys a partir d'aleshores. Si en lloc tenir en compte el conjunt de llars es consideressin solament les llars joves, l'esforç econòmic pràcticament es doblaria. És el que explica la poca presència de parelles joves amb fills a la ciutat

${ }^{24}$ Segons informació apareguda en el País, de novembre, 2006, a Catalunya el treball precari significa ja el 27\% del total d'ocupats. Per als joves la proporció supera el $50 \%$ dels contractes.

${ }^{25}$ Així ho escrivia el directiu d'una companya d'inversió immobiliària a la revista l'Actualidad Económica (1974) referirse a la política franquista d'accés a l'habitatge: "si se hubiera promovido una política de renta en vez de una de obra, hoy retrospectivamente comprobaríamos como la estabilidad social alcanzada era inferior a la conseguida econ esa política de ventas". Citat a H. Capel Capitalismo y morfología urbana de España. Libros de la Frontera. Barcelona, 1981. També l'Engels ho havia deixat clar "el treballador esdevé lligat de mans i peus".

${ }^{26}$ El País, 2 de desembre de 2006, Opinió, pàg. 17 i 18.

${ }^{27}$ El País, diumenge 2 de setembre de 2007, pàg 73. L.D, Madrid Economia.
} 